\title{
Design of bionic locust mouthparts stubble cutting device
}

\author{
Jiale Zhao ${ }^{1,2}$, Mingzhuo Guo ${ }^{1 *}$, Yun $\mathrm{Lu}^{1,2}$, Dongyan Huang ${ }^{1,2}$, Jian Zhuang ${ }^{1,2}$ \\ (1. College of Biological and Agricultural Engineering, Jilin University, Changchun 130022, China; \\ 2. The Key Laboratory of Bionic Engineering, Ministry of Education, Jilin University, Changchun 130022, China)
}

\begin{abstract}
Given the technical problems of low maize stubble breaking efficiency, large cutting torque and high power consumption faced during springtime no-till planting in Northeast China, we designed a high-performance coupling bionic stubble cutting device capable by integrating the structure (multi-segment and serrate) and cutting mode (isokinetic and symmetrical) of locust mouthparts. Methods of bionic construction, mechanism design, theoretical analysis, parameter optimization, Arduino systems and intelligent control were combined to design a planetary gear mechanism and an intelligent speed control system. In particular, the bionic cutting blade could reconstruct the multi-segment and serrate structure of locust mouthparts, while the planetary gear mechanism and the intelligent speed control system jointly comprised the bionic drive system, which could simulate the isokinetic and symmetrical cutting mode, thereby bionically coupling morphological structures and movement patterns. Analysis of comparative tests showed the coupling bionic cutting device could reduce the cutting torque by $26.6 \%-31.6 \%$ and the power consumption by $21.9 \%-26.1 \%$. This work confirmed that coupling bionic method can significantly improve the stubble cutting efficiency, which was a valuable contribution to the design of stubble cutting device for no-till planter.
\end{abstract}

Keywords: bionics, locust mouthparts, cutting device, corn stubble

DOI: $10.25165 /$ j.ijabe.20201301.5031

Citation: Zhao J L, Guo M Z, Lu Y, Huang D Y, Zhuang J. Design of bionic locust mouthparts stubble cutting device. Int J Agric \& Biol Eng, 2020; 13(1): 20-28.

\section{Introduction}

Maize is the most important food crop in China, but its yields mainly depend on the quality of cultivated lands ${ }^{[1]}$. In the planting mode of stubble-returning, maize stubbles are reserved in soils after autumn harvest and then broken before the springtime planting next year ${ }^{[2,3]}$. This planting mode can preventing soil erosion and improving soil organic contents and pore structures, and thus has become the major popularized agriculture method throughout China $^{[4,5]}$. However, the stubble breaking operations before springtime planting are limited by heavy resistance and high power consumption, which largely complicate the production costs and severely restrict the popularization of this mode ${ }^{[6]}$. Thus, it is urgent to study the mechanism of resistance and consumption reduction during stubble cutting and design stubble breaking mechanisms for efficient cutting, which will significantly promote the stubble-returning agricultural mode and thereby improve the quality of cultivated lands.

Researchers have conducted extensive research to efficiently reduce the resistance and energy consumption during stubble breaking operations. For instance, Liu investigated changing the

\section{Received date: 2019-03-15 Accepted date: 2020-01-16}

Biographies: Jiale Zhao, $\mathrm{PhD}$, Associate Professor, research interests: bionic intelligent agricultural machinery and conservation tillage technology. Email: zhaojiale0313@163.com; Yun Lu, PhD, research interests: bionic intelligent agricultural machinery and conservation tillage technology. Email: 836035570@163.com; Dongyan Huang, PhD, Professor, research interests: agricultural machinery design, Email: cchdy760829@sina.com; Jian Zhuang, $\mathrm{PhD}$, Associate professor, research interests: biomimetic materials engineering, Email: zhuangiian@163.com.

*Corresponding author: Mingzhuo Guo, PhD, research interests: conservation tillage technology. School of Biological and Agricultural Engineering, Jilin University, Changchun 130022, China. Tel: +86-18504311293, Email: guomingzhuo@outlook.com. cutting method of the litchi can reduce the cutting resistance. The above studies promoted further research on the stubble cutting and anti-blocking device and the mechanisms of resistance and consumption reduction $^{[7]}$. Furthermore, the gradual development of novel engineering techniques including bionics makes it possible to further enhance the working performances of agriculture machine.

As an emerging engineering discipline, bionics has been extensively applied to the engineering field. After hundreds of millions of years of evolution, organisms can always utilize the materials available and the minimum energy consumption to 'create' the organism structure with the optimal functions. The principles of bionics are exactly to provide inspirations for humans to solve technical problems by characterizing the biological excellent structures ${ }^{[8]}$. So far, the use of bionic principles to solve problems in the field of agriculture machine has gradually attracted wide attention. For instance, Tian et al. ${ }^{[9]}$ designed sugarcane cutting blades. It was found the bionic design of cutter structures could modestly reduce the resistance and power consumption of root-stem cutting for many types of crops.

Along with further development of bionics, the bionics design methods have evolved from the structural bionics of single functions to coupling bionic design, in which the effects of multiple coupling elements of movement - structure - materials are studied simultaneously ${ }^{[10,11]}$. For instance, Ren et al. ${ }^{[12]}$ and Li et al. ${ }^{[13]}$ found the structure-movement coupling bionic design could further improve the cutting performances.

Thus, in this study, based on the above coupling bionic methods, we designed a bionic stubble cutting device, which could simulate the morphologic characteristics and movement patterns of locust mouthparts in cutting plant fibers. Furthermore, through theoretical analysis, test optimization and regression analysis, we clarified the coupling mechanism of how bionic structures and bionic movement patterns affected the stubble cutting 
performances, and thereby theoretically and technically support the design of high-performance stubble cutting device. The research papers in this paper are mainly applicable to the black soil planting areas in Northeast China.

\section{Materials and methods}

\subsection{Analysis of biologic prototypes}

The biologic prototype used in this research is the Locusta migratoria manilensis Meyen, collected from Jilin University Agricultural Experiment Base in Jilin Province. Locusta migratoria manilensis is a common insect belonging to Orthopteran and mainly feed on maize, rice and other food crops ${ }^{[14]}$. Their mouthparts have evolved into structures and biting modes that can efficiently and low-resistantly cut gramineous plants. The locust mouthparts structure consists of a group of symmetrical palates $^{[15]}$ (Figure 1).

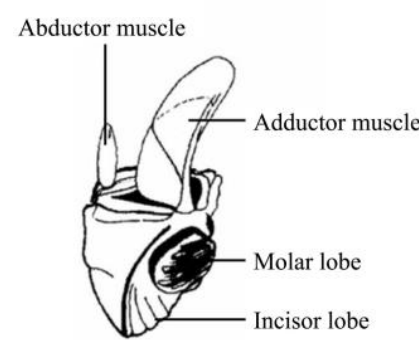

a. Structure of locust palate

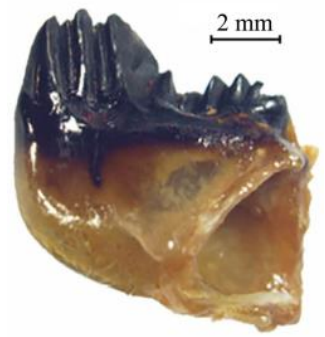

b. Structure of top incisor lobe
Figure 1 Schematic diagram of locust mouthparts structure

The frontend bilateral incisor lobes each have 4 sharp-peaked canine teeth, which are about $1 / 3$ the length of palates and form a multi-segment and serrate cutting-edge structure. This structure can effectively avoid extension of plant fibers and thereby reduce the cutting torque required. Meanwhile, the base of palates is composed of strong adductor muscle tendons and small abductor muscle tendons. Through rapid extension and stretching, the two bundles of muscles can flexibly control the palate rotation ${ }^{[16]}$. During the feeding process, the two palates simultaneously revolve inwards, and symmetrically cut the plant fibers at constant speed like scissors, which efficiently reduce the cutting torque. The coupling bionic stubble cutting device designed here could imitate the structure and cutting mode of locust mouthparts upon feeding, thereby increasing the working effect of stubble cutting.

\subsection{Structural design and working principle of coupling bionic stubble cutting device}

The coupling bionic stubble cutting device mainly consisted of a bionic drive system and bionic cutting blades (forward resolving and reverse resolving) (Figure 2a). Specifically, the bionic cutting blades were installed with bionic cutting edges, curves of which were designed as bionic locust mouthparts incisor lobes. The forward resolving and reverse resolving bionic cutting blades had 9 and 18 bionic cutting edges, respectively. The bionic drive system consisted of a planetary gear mechanism, a stepping motor, an intelligent speed control system, and a drive shaft (Figure 2b). In particular, the intelligent speed control system was composed of drivers, encoders and display modules. The drive shaft was connected with the stepping motor via a coupler, while the forward resolving bionic cutting blade was fixed via a shaft sleeve to the drive shaft (Figure 2c). The reserve resolving bionic cutting blade was bolted onto the annular gear of the planetary gear mechanism. The planetary gear mechanism consisted of 1 sun gear, 3 planetary gears, and 1 annular gear (Figure 2d). In particular, the sun gear was fixed via the key joint to the drive shaft.

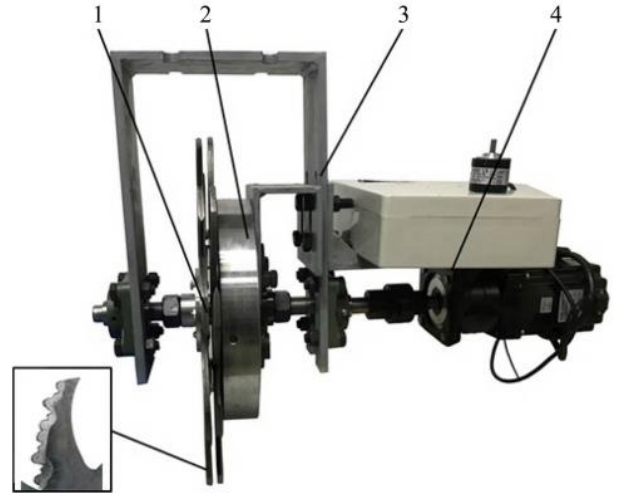

a. Main structure of the stubble cutting device

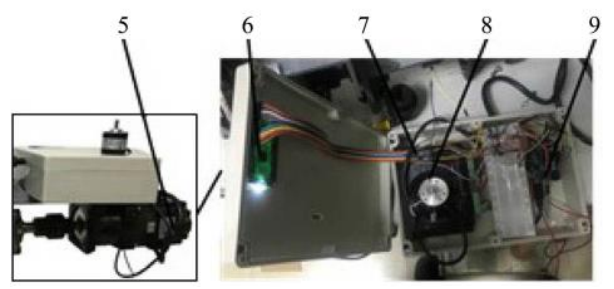

b. Intelligent speed control system

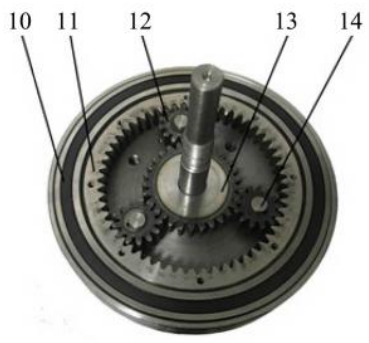

c. Planetary gear mechanism

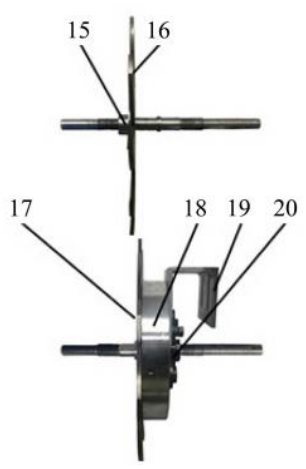

d. Power transmission
1. Bionic cutting blade 2. Planetary gear mechanism 3. Connection mechanism 4. Intelligent drive system 5. Stepping motor 6. Display module 7. Driver 8. Encoder 9. Main control chip 10. Annular gear bearing 11. Annular gear 12. Sun gear 13. Planetary gear 14. Planetary gear shaft 15. Fixation shaft sleeve 16. Forward resolving bionic cutting blade 17. Reserve resolving bionic cutting blade 18. Shell 19. Anti-resolving support 20. Bearing seat

Figure 2 Whole structure of the coupling bionic stubble cutting device

The coupling bionic stubble cutting device was installed in the most front of the no-till planter (Figure 3). During the operation, the drive shaft transferred the torque, outputted from the stepping motor to the forward resolving bionic cutting blade and the planetary gear mechanism ${ }^{[17]}$. Particularly, when the forward resolving bionic blades were cutting, the planetary gear mechanism was at the reverse speed-changing resolution, and thereby drove the reserve resolving bionic cutting blades into reserve resolving cutting, so that the two bionic cutting blades were capable of coaxial reverse rotation. The intelligent speed control system, via the encoder, could collect the real-time advancing speed $(v)$ of the machine, and via the Arduino main control chip ${ }^{[18,19]}$, could compute the real-time $v$ and corresponding blade rotation speed $(\omega)$. Finally, via the 3ND2283-600 driver, the stepping motor was driven to rotate at $\omega$ to output the torque. As a result, the average cutting linear velocities of the two bionic cutting blades were nearly equal, and thereby the isokinetic and symmetrical cutting of the locust mouthparts during feeding was simulated. Therefore, the design of the bionic cutting movement was realized, so as to efficiently cut stubbles. 


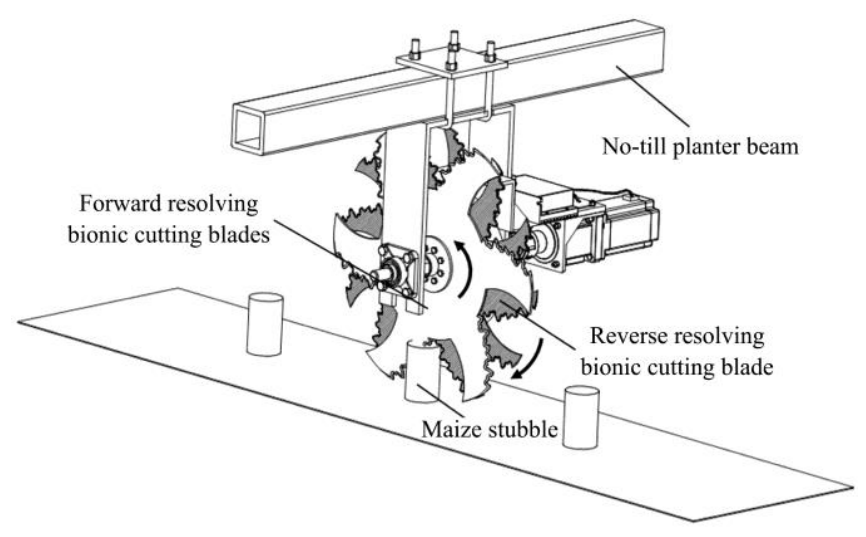

Figure 3 Working schematic diagram

\subsection{Planetary gear mechanism}

During the operation, the drive shaft and planetary gear mechanism drove the forward and reverse resolving bionic cutting blades, respectively, so as to realize the isokinetic and symmetrical cutting. Currently, the cutting linear velocities at any point on the forward and reverse resolving bionic cutting blades were:

$$
\begin{gathered}
v_{i}=\omega r_{i}-v \\
v_{j}=i \omega r_{j}+v
\end{gathered}
$$

where, $v_{i}$ is the cutting linear speed at a random point on forward resolving bionic cutting blade, $\mathrm{m} / \mathrm{s} ; v_{j}$ is the cutting linear speed at a random point on reverse resolving bionic cutting blade, $\mathrm{m} / \mathrm{s} ; v$ is advancing speed of machine, $\mathrm{m} / \mathrm{s} ; r_{i}$ is radius of gyration at any random point on forward resolving cutting blade, $\mathrm{mm} ; r_{j}$ is radius of gyration at any random point on reverse resolving cutting blade, $\mathrm{mm}$; $\omega$ is rotation speed of forward resolving cutting blade, $\mathrm{m} / \mathrm{s}$; $i$ is the variable speed ratio.

It is clear from Equations (1) and (2) that the average cutting linear velocities of forward and reverse resolving bionic cutting blades were:

$$
\begin{aligned}
& v_{1}=v+\frac{\omega}{n} \sum_{i=1}^{n} r_{i} \\
& v_{2}=v+\frac{i \omega}{n} \sum_{j=1}^{n} r_{j}
\end{aligned}
$$

To let the coupling bionic stubble cutting device simulate the isokinetic and symmetrical cutting of locust mouthparts, we maintained the average cutting linear velocities of the forward and reverse resolving bionic cutting blades approximately equal ${ }^{[20]}$. Thus, the ratio among the rotation speed of the drive shaft, the advancing speed of the machine, and the speed changing of the planetary gear mechanism was:

$$
\omega=\frac{2 v}{\frac{1}{n}\left(i \sum_{j=1}^{n} r_{j}-\sum_{i=1}^{n} r_{i}\right)}
$$

According to torque equation $P=T \omega$, when the output power $P$ of the drive mechanism was constant, a smaller drive shaft rotation speed $\omega$ led to a larger output torque $T$. During operation, the cutting mechanism with a larger difference between the output torque from the stubble cutting mechanism and the cutting torque needed by the operation can more easily cut stubbles. Equation (5) suggests the rotation speed of the drive shaft decreases with the rise in the variable speed ratio of the planetary gear mechanism, and thus, the variable speed ratio should be set as the maximum value of the selective range.

The machining of the sun gear should be set according to the gear module national standard GB1357-87 preferentially, together with consideration into the overall structure dimensional parameters of the mechanism and the machining difficulty, while ensuring the moving stability of the mechanism. Thus, we set the sun gear modulus $m=3$, gear thickness $=20 \mathrm{~mm}$, and tooth number $25<Z_{1}<31$. To make the overall inner space of the mechanism match, we set the annular gear tooth number $54<Z_{3}<56$. The relationship between the variable speed ratio of the planetary gear mechanism and the annular gear diameter is:

$$
d=Z_{1} i m+2 h a^{*} m
$$

The addendum coefficient $h a^{*}$ in Equation (6) was set as 1, and then $1.62<i<1.92$. The largest theoretical transmission ratio of 1.92 was selected in the design. Based on the gear design software KISSsoft, the tooth number of sun gear $Z_{1}$ was 29 , the tooth number of planetary gear $Z_{2}$ was 13 , and the tooth number of annular gear $Z_{3}$ was 55 . Thus, we determined the parameters of the planetary gear mechanism (Table 1 ). The real transmission ratio was 1.897 , which was substituted into the simulation module, and the transmission contact strength and the transmission curving strength obeyed the design requirements ${ }^{[21]}$.

Table 1 Planetary gear transmission mechanism parameters

\begin{tabular}{lccc}
\hline \multicolumn{1}{c}{ Parameters } & Sun gear & Planetary gear & Annular gear \\
\hline Tooth number $Z$ & 29 & 13 & 55 \\
Modulus $m$ & 3 & 3 & 3 \\
Quantity & 1 & 3 & 1 \\
Addendum $h a / \mathrm{mm}$ & 3 & 3 & 3 \\
Dedendum $h f / \mathrm{mm}$ & 3.75 & 3.75 & 3.75 \\
Tooth height $h / \mathrm{mm}$ & 6.75 & 6.75 & 6.75 \\
Reference circle diameter $d / \mathrm{mm}$ & 87 & 39 & 165 \\
Addendum circle diameter $d a / \mathrm{mm}$ & 93 & 45 & 159 \\
Dedendum circle diameter $d f / \mathrm{mm}$ & 79.5 & 31.5 & 172.5 \\
Center moment $a / \mathrm{mm}$ & 63 & 63 & 63 \\
End-face stress angle $/\left(^{\circ}\right)$ & 20 & 20 & 20 \\
\hline Variable speed ratio $i$ & & 1.897 & \\
\hline
\end{tabular}

\subsection{Intelligent speed control system}

In order to achieve isokinetic and symmetrical cutting mode, we design the intelligent speed control system, which can control and adjust the rotation speed of the drive shaft according to advancing speed of the machine. The intelligent speed control system consisted of an Arduino main control chip, a 110BYG350D Leadshine stepping motor, a 3ND2283-600 stepping motor driver, an OMRON incremental photoelectric encoder ${ }^{[22]}$, a DM1602C LCD display module, and an HC-06 Bluetooth module, which achieved the signal acquisition, analysis and processing. The hardware framework of the system was showed in Figure 4.

U1 was the Arduino chip used to maintain the whole system under normal working, while U2 was the incremental photoelectric encoder used to collect the real-time advancing speed of the whole set. This system adopted AB two-phase pulse signals to judge the rotating direction and rotating speed. The output way and output signals of the encoder were showed in Figure 5. The A-phase and B-phase pulse signals of the encoder U2 were captured and transformed to pulse numbers, followed by computation of advancing speed. The Arduino system calculated the real-time rotating speed of the stepping motor and the pulse signal frequency of the driving stepping motor according to Equation (5).

U3 was the 3ND2283-600 stepping motor driver used to control the 110 three-phase hybrid stepping motor in the driving system $^{[23]}$. This driver was connected via PNP output wire connection mode with the controller. U4 was the HC-06 Bluetooth module used to connect with the Android system for 
communication, and data transmission, display and command control were conducted on relevant software. During the working, the LCD screen displayed the real-time advancing speed and cutting blade rotation speed.

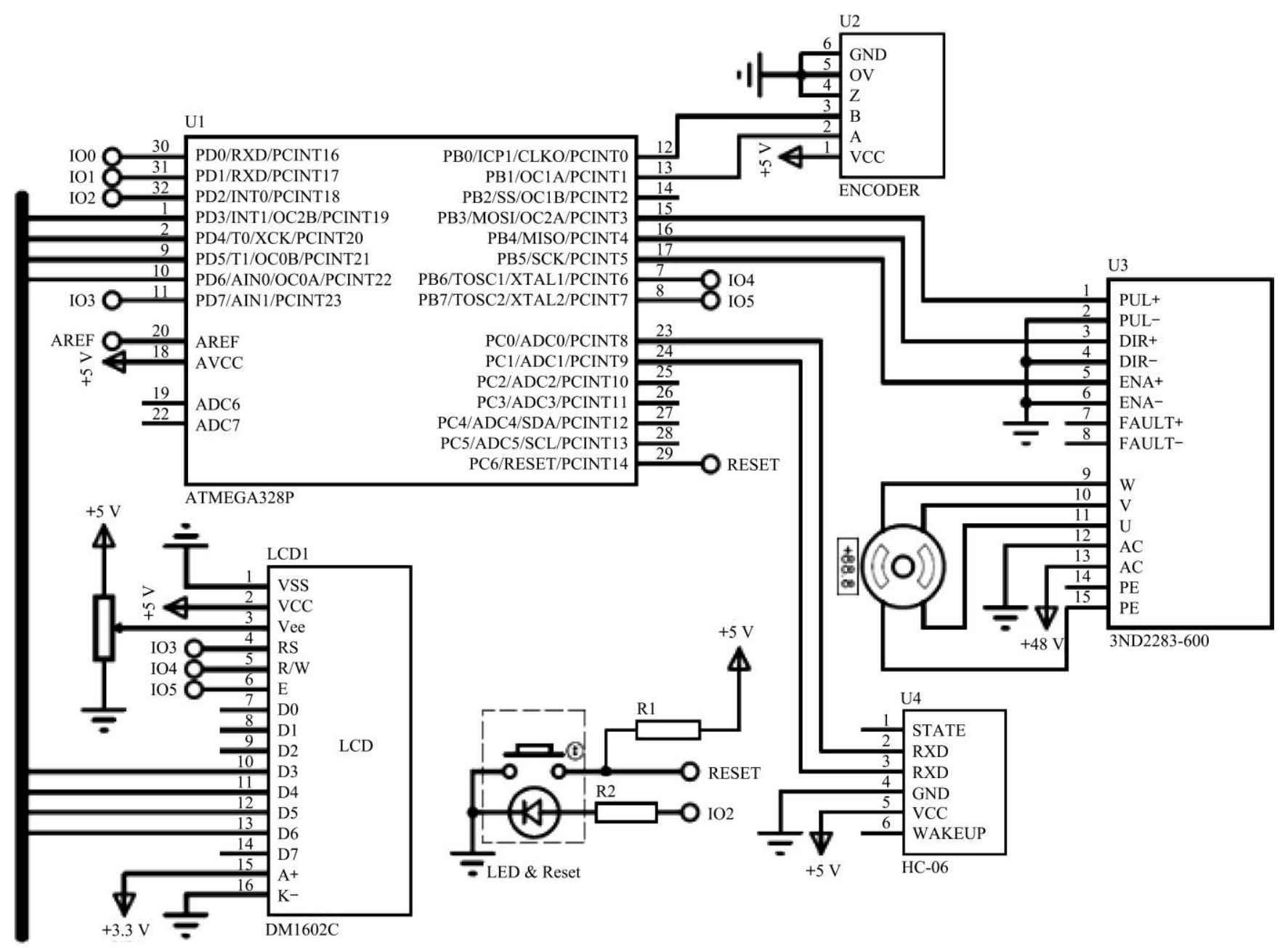

Figure 4 Schematic diagram of system circuits

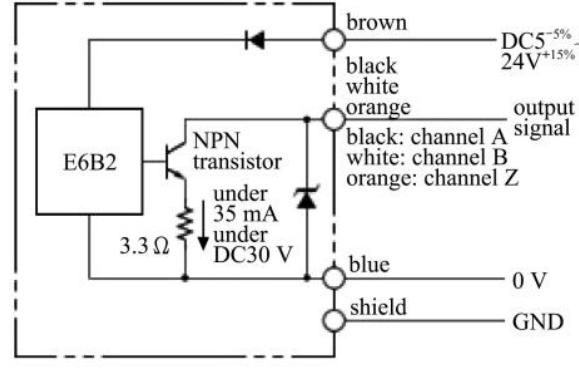

a.



b.

Figure 5 (a) Output loops of the E6B2-CWZ6C encoders, (b) Output pulse signals of the E6B2-CWZ6C encoders

\subsection{Design of bionic blades}

As the forward resolving and reverse resolving bionic cutting blades were working (Figure 3), they cut mainly through the several bionic cutting edges extending at the lateral side. The stubble cutting of the bionic blade is similar to the locust mouthparts cutting plant fibers, and thus according to the bionic theory, with the locust mouthparts palates as the prototype and by extracting the outline curve of the palate incisor lobe, we applied the efficient cutting characteristics of the incisor lobe into the edges of stubble cutting blades, aiming to achieve the efficient stubble cutting. The palate samples of locusts were observed under a stereomicroscope. Since the real sizes of the incisor lobe outline structures were tiny and not convenient for acquisition, we intercepted and magnified the images of this part, and showed the detail of the original image in Figure 6. Then the original image was transformed into a grayscale image, corroded image, expanded image, filled image, two-value image in sequence through the commands rgb2gray, imerode, imdilate, im2bw, Imfill and edge in MATLAB, respectively ${ }^{[24]}$. Finally, curve outline coordinates were obtained.

The coordinates were plotted via the LOG algorithm into the final boundary graphs, and the structures of resulting curves were complete and clean, which was basically consistent with the original images. According to the continuity of the curves, each wave crest was considered as a unit, and the whole outline curve was divided into 5 parts, which were named as curves 1 to 5 , respectively. The obtained outline boundaries and the curves were shown in Figure 7. 


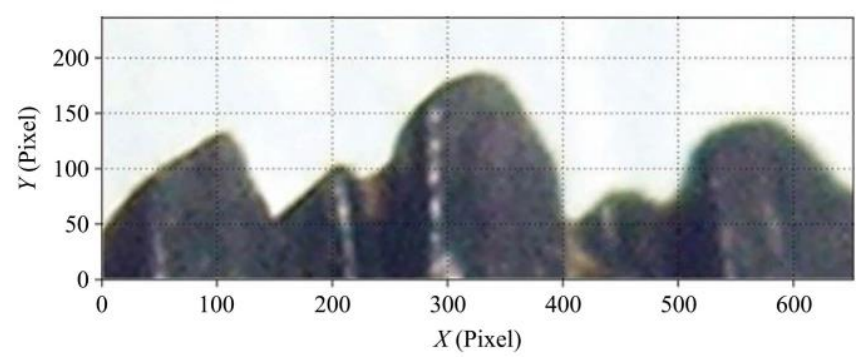

Figure 6 Detailed image of extracted locust incisor lobe
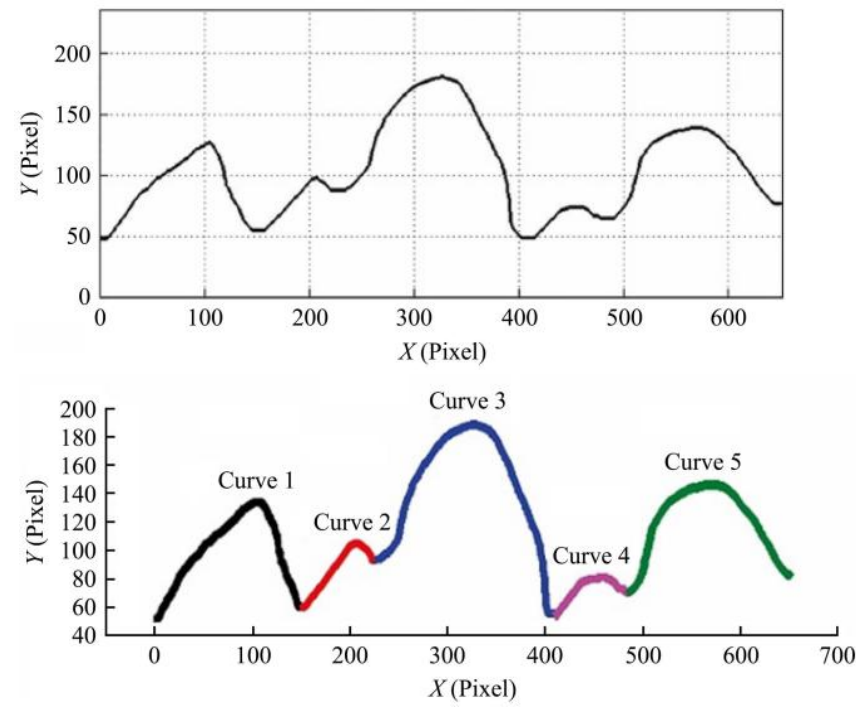

Figure 7 Outline boundaries and curve division

The above 5 curves were fitted separately on Origin into the sixth order polynomial ${ }^{[25]}$ :

$$
\varphi(x)=\text { Intercept }+B_{1} x^{1}+B_{2} x^{2}+B_{3} x^{3}+B_{4} x^{4}+B_{5} x^{5}+B_{6} x^{6}
$$

The fitting results are shown in Table 2. The $R^{2}$ is over 0.998 in all the fitted equations of the 5 curves, which indicates the high fitting effect. The fitted equations were plotted on the rectangular coordinate system, and the residual errors were mostly smaller than 10 , indicating the fitting precision met the processing requirement.

Table 2 Results of parameter fitting

\begin{tabular}{cccccc}
\hline Parameter & Curve1 & Curve 2 & Curve 3 & Curve 4 & Curve5 \\
\hline Intercept & 53.5975 & 59.7921 & 91.6104 & 54.8803 & 64.7927 \\
SD of Intercept & 0.9151 & 0.3213 & 2.0163 & 0.4069 & 0.1815 \\
$B_{1}$ & 0.15502 & 0.39257 & 0.16624 & 0.22625 & 0.12789 \\
SD of $B_{1}$ & 0.17350 & 0.12412 & 0.28691 & 0.15758 & 0.18324 \\
$B_{2}$ & 0.10294 & 0.06910 & 0.08640 & 0.08474 & 0.06375 \\
SD of $B_{2}$ & 0.01030 & 0.01496 & 0.01375 & 0.01903 & 0.00980 \\
$B_{3}$ & -0.00365 & -0.00431 & -0.00166 & -0.00410 & -0.00217 \\
SD of $B_{3}$ & $2.61 \times 10^{-04}$ & $7.67 \times 10^{-04}$ & $2.83 \times 10^{-04}$ & $9.78 \times 10^{-04}$ & $2.258 \times 10^{-04}$ \\
$B_{4}$ & $5.43 \times 10^{-05}$ & $1.30 \times 10^{-04}$ & $1.38 \times 10^{-05}$ & $8.93 \times 10^{-05}$ & $2.64 \times 10^{-05}$ \\
SD of $B_{4}$ & $3.19 \times 10^{-06}$ & $1.89 \times 10^{-05}$ & $2.80 \times 10^{-06}$ & $2.42 \times 10^{-05}$ & $2.56 \times 10^{-06}$ \\
$B_{5}$ & $3.63 \times 10^{-07}$ & $1.79 \times 10^{-06}$ & $5.51 \times 10^{-08}$ & $9.99 \times 10^{-07}$ & $1.46 \times 10^{-07}$ \\
SD of $B_{5}$ & $1.86 \times 10^{-08}$ & $2.23 \times 10^{-07}$ & $1.32 \times 10^{-08}$ & $2.84 \times 10^{-07}$ & $1.36 \times 10^{-08}$ \\
$B_{6}$ & $8.83 \times 10^{-10}$ & $8.84 \times 10^{-09}$ & $8.31 \times 10^{-11}$ & $4.49 \times 10^{-9}$ & $3.02 \times 10^{-10}$ \\
SD of $B_{6}$ & $4.13 \times 10^{-11}$ & $9.98 \times 10^{-10}$ & $2.38 \times 10^{-11}$ & $1.28 \times 10^{-9}$ & $2.76 \times 10^{-11}$ \\
$R^{2}$ & 0.99408 & 0.99897 & 0.9881 & 0.9947 & 0.98948 \\
\hline
\end{tabular}

Equation (7) was selected as the curve structure of the bionic cutting edge, which considered both the no-till planter structure and the sizes of the traditional stubble cutting plate (Figure 8 ). The resolving diameters of the bionic cutting blades were $450-500 \mathrm{~mm}$,

and the arc length $\widehat{A B}$ and height $h$ of single bionic locust mouthparts blades were:

$$
\begin{gathered}
A B=\frac{2 \pi(D / 2-h)}{n} \\
D-d=2 h
\end{gathered}
$$

where, $D$ is the diameter of bionic cutting blades, $\mathrm{mm} ; d$ is the diameter of lade base circle, $\mathrm{mm}$.

The diameter of lade base circles, $d$, was approximately equal to the bearing outside diameter of the annular gear (Figure 8b). The height of single bionic locust mouthparts blades was $50 \leq h \leq 80$. For convenient processing, we set $h=80 \mathrm{~mm}$, and the fitted outline curve of the incisor lobe was magnified as the same scale, so that single blades all had 2 segments of bionic cutting-edge curves. As the variable speed ratio was approximately 2 , the ratio of cutting-edge number between forward and reserve resolving blades is $1: 2$, and the same structure was used at these two cutting-edges (Figure 8a). The final processing effect is illustrated in Figure 8c.

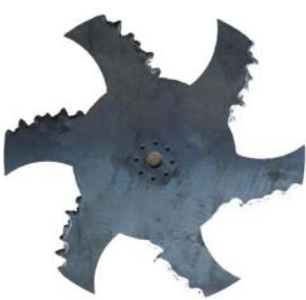

a. Forward resolving bionic cutting blade Figure 8

Tests and methods

\subsection{Test factor selection}

Single-factor four-level trials were conducted to clarify the low-resistance mechanism and working effects of bionic stubble cutting device ${ }^{[26]}$. During the trials, individual maize stubbles were cut by using 4 different cutting devices. The specific grouping is shown in Table 3. Each test was repeated 5 times, and the advancing speed of the trial vehicle was fixed at 4,6 or 8 $\mathrm{km} / \mathrm{h}$. After each test, the corresponding changing curve of cutting torque was recorded, so as to validate the anti-resistance performance of the coupling bionic stubble cutting device. The straw stubbles after cutting were classified and stored, so as to compare the cutting effects of the 4 devices.

Table 3 Test grouping of cutting device

\begin{aligned} & \hline Type \multicolumn{1}{c}{ Status of stubble cutting device } \\ & \hline S1 $\begin{array}{l}\text { Two bionic cutting blades were installed, and the bionic stubble } \\ \text { cutting device of symmetrical cutting was tested. }\end{array} \\ &$ S2 $\begin{array}{l}\text { One bionic cutting blade was installed, and the bionic stubble cutting } \\ \text { device of unilateral cutting was tested. }\end{array} \\ &$ S3 $\begin{array}{l}\text { Two common stubble cutting blades were installed, and the stubble } \\ \text { cutting device of symmetrical cutting was tested. }\end{array} \\ &$ S4 $\begin{array}{l}\text { One common stubble cutting blade was installed, and the stubble } \\ \text { cutting device of unilateral cutting was tested. }\end{array}\end{aligned}$

The major working performance of a stubble cutting device is decided by the largest cutting torque and cutting power consumption. A smaller maximum cutting torque is more favorable for stubble cutting, and lower cutting power consumption saves costs. Thus, cutting torque and cutting power consumption were selected as two trials indicators.

\subsection{Test equipment and materials}

The test maize variety, Xianyu335, is most commonly-planted in Northeast China. The maize was planted on May 21, 2017, and 
the test samples were stalks of maize harvested from October 1 to 7 , 2017 at Lishu Town, Changchun, Jilin, China $\left(35.897776^{\circ} \mathrm{N}\right.$, $83.961532^{\circ} \mathrm{W}$ ). The stubbles were collected on May 20, 2018, and during the whole collection process, the air humidity was over $60 \%$ and the air temperature was $6^{\circ} \mathrm{C}-14^{\circ} \mathrm{C}$. All specimens were packed in plastic wrap immediately after they were harvested, and then transported to the laboratory. Tests for each sample were conducted within $140 \mathrm{~min}$ after harvesting. All the tests were conducted at the laboratory of Jilin University in Changchun, China. Before the cutting test, approximately $20 \%$ of the specimens were randomly selected for the measurement of average moisture content. Those specimens were weighed, oven-dried at $102^{\circ} \mathrm{C}$ for $24 \mathrm{~h}$, and then weighed again (ASABE Standards, 2006). The average of measured moisture content was $81.2 \%$. The soil conditions in soil bins were consistent as those in the field. The soil preparation process used here was: artificial soil leveling - artificial spraying burying stubbles - compacting, the detail of soil physiochemical property is shown in Table 4. The main test instruments were: 4 types of stubble cutting devices, Hall sensors(Honeywell company, USA), AKC-205B torque sensors (Yuke Taiji Electronics Co., Ltd, Beijing, China), DI-1100 data acquisition cards (DATAQ Instruments Co., Ltd, USA), computer (HP Development Co., Ltd, USA), soil bins and trial vehicles (Jilin University, China), tapeline, cutting rings (volume $=100 \mathrm{~cm}^{3}$, Hua Wang Co., Ltd, China), electronic balance (Yajin Electronic Technology Co., Ltd, China), MS-350 moisture meter (Tsingtao Toky Instruments Co., Ltd, China), SC-900 soil compaction meter (Spectrum Technologies Co., Ltd, USA), and soil thermometer (Shenzhen Baiji Biological Technology Co., Ltd, China) ${ }^{[27,28]}$.

Table 4 Soil physiochemical properties at depth 0-100 $\mathrm{mm}$ in soil-bin trial fields

\begin{tabular}{lc}
\hline \multicolumn{1}{c}{ Physiochemical property } & Data \\
\hline Soil compaction $/ \mathrm{MPa}$ & 40.2 \\
Soil bulk density $/ \mathrm{g} \cdot \mathrm{cm}^{-3}$ & 1.237 \\
Soil water content $/ \%$ & 21.2 \\
Soil temperature $/{ }^{\circ} \mathrm{C}$ & 13.2 \\
$\mathrm{pH}$ & 7.08 \\
Organic matter $/ \%$ & 3.78 \\
Total nitrogen $/ \%$ & 0.13 \\
Available $\mathrm{K}\left(\mathrm{K}_{2} \mathrm{O}\right) / \mathrm{mg} \cdot \mathrm{kg}^{-1}$ & 173.2 \\
Available $\mathrm{P}\left(\mathrm{P}_{2} \mathrm{O}_{5}\right) / \mathrm{mg} \cdot \mathrm{kg}^{-1}$ & 16.5 \\
\hline
\end{tabular}

\subsection{Test system and methods}

The test was designed to reflect as closely possible the real cutting conditions for blades in terms of both test material and tool material. During the tests, stubbles were buried in soil bins. The upper zone A of each sample was at the same level as the soil surface. The distance between stubbles was $100 \mathrm{~cm}$, and there were totally 5 stubbles (Figure 9a). Two Hall sensors were installed at two ends, respectively ${ }^{[29]}$. The stepping motor and the stubble cutting device were installed on a trial vehicle, while the two ends of each torque sensor were connected with the transmission shaft of the stubble cutting device and the output shaft of the stepping motor, respectively (Figure 9b). During the trials, the trial vehicle drove the stubble cutting device to advance at a constant speed, while the stubble cutting device under rotationally cutting was controlled by the stepping motor and intelligent speed control system. When the stubble cutting device reached Hall sensor I, the torque sensor started to collect torque information and transmitted to the data acquisition card. When the stubble cutting device reached Hall sensor II, the torque sensor stopped data transmission. The data collected were converted via Equation (1) into means on MATLAB, which were used as the test results.

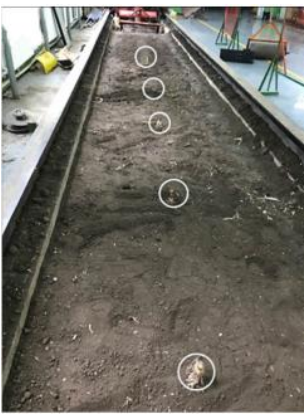

a. Layout scheme of maize stubbles



b. Bionic locust mouthparts stubble cutting device
Figure 9 Soil bin test

During the tests, the trial vehicle and the stepping motor drove the stubble cutting device to cut stubbles, and the torque sensor transferred the torque value and corresponding time into the data acquisition card. The cutting torque - cutting time curves were plotted on MATLAB, so as to observe the changing trend of cutting torque and find out the maximum cutting torque. The cutting power consumption could be determined via Equation (10) on MATLAB by collecting the cutting torque and cutting time ${ }^{[30,31]}$.

$$
\left\{\begin{array}{l}
T=g(t) \\
W=\sum P \Delta t=\sum \omega T \Delta t=\int \omega g(t) d t
\end{array}\right.
$$

where, $T$ is the cutting torque, $\mathrm{N} \cdot \mathrm{m} ; W$ is the cutting power consumption, $\mathrm{J} ; P$ is the cutting power, $\mathrm{W} ; t$ is the cutting time, $\mathrm{s}$; $\omega$ is the motor speed, $\mathrm{rad} / \mathrm{s}$.

\section{Results and discussion}

The maximum cutting torque data of stubbles over the 4 types of cutting devices are shown in Figure 10. Clearly, the cutting torque - time curves of S1 and S3 at 3 working velocities were all divided into 3 stages $^{[32]}$. With Figure 10a as an example, $O A\left(O A^{\prime}\right)$ was the first cutting stage, and the cutting torque gradually rose and maximized. $A B\left(A^{\prime} B^{\prime}\right)$ was the second stage, where the cutting torque gradually declined. $B C\left(B^{\prime} C^{\prime}\right)$ was the third stage, where the cutting torque rapidly dropped to the minimum value.

The cutting torque - time curves of S2 and S4 at different working velocities were all divided into 3 stages. With Figure 10b as an example, $O D\left(O D^{\prime}\right)$ was the first cutting stage, where the cutting torque gradually rose and maximized. $D E\left(D^{\prime} E^{\prime}\right)$ was the second stage, where the cutting torque gradually declined. $E F\left(E^{\prime} F^{\prime}\right)$ was the third stage, where the cutting torque rapidly dropped and quickly rose again, but after reaching a very low peak, it gradually declined again.

The maximum cutting torque of the four cutting types were in the order $\mathrm{S} 1<\mathrm{S} 2<\mathrm{S} 3<\mathrm{S} 4$. Compared with $\mathrm{S} 4$, the maximum cutting torque of S1, S2, and S3 decreased by $31.6 \%, 24.3 \%$ and $14.8 \%$ at the advancing speed of $4 \mathrm{~km} / \mathrm{h}$, and declined by $26.6 \%$, $19.6 \%$ and $10.2 \%$ at $6 \mathrm{~km} / \mathrm{h}$, and reduced by $29.7 \%, 18.8 \%$ and $13.6 \%$ at $8 \mathrm{~km} / \mathrm{h}$, respectively (Table 5 ).

Table 5 Maximum cutting torque of the four cutting types at different advancing speed

\begin{tabular}{ccccc}
\hline \multirow{2}{*}{$\begin{array}{c}\text { Advancing speed } \\
/ \mathrm{km} \cdot \mathrm{h}^{-1}\end{array}$} & \multicolumn{4}{c}{ Maximum cutting torque/N·m } \\
\cline { 2 - 5 } & $\mathrm{S} 1$ & $\mathrm{~S} 2$ & $\mathrm{~S} 3$ & $\mathrm{~S} 4$ \\
\hline 4 & 63.062 & 69.824 & 78.541 & 92.232 \\
6 & 59.042 & 64.635 & 72.178 & 80.392 \\
8 & 50.648 & 58.543 & 62.281 & 72.121 \\
\hline
\end{tabular}



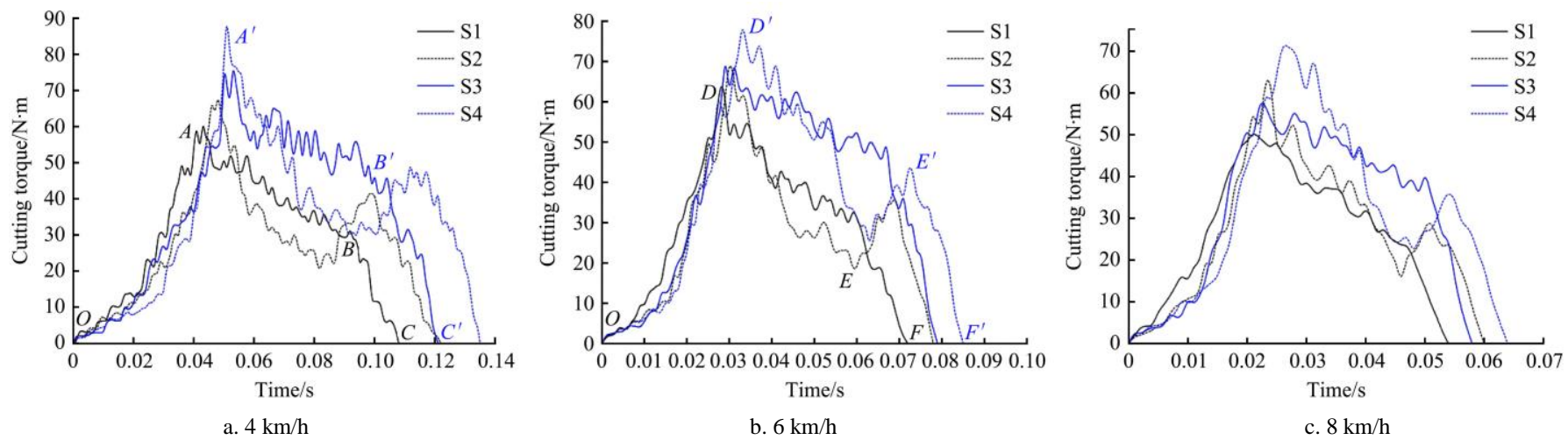

Figure 10 Cutting torque - time curves of four different types of cutting devices at different velocities

\subsection{Analysis of the first cutting stage}

The maize stubbles consist of fiber-dominated outer rind and low-hardness pith, and the outer rind fibers are rich in tough celluloses $^{[33]}$ (Figure 11). When maize stubbles are cut by blades, the fiber structures of outer rind are under both tensile and cutting actions (Figure 12). As the blade is gradually pulled, the deformation of the outer rind is gradually increased, and the tensile stress and shear stress are enhanced accordingly. Before the stress maximizes, the outer rind will not break. At this stage, the outer rind and pith do not enter the cutting stage, but are under compressed deformation. Thus, at the first cutting stage, the cutting load $^{[34]}$ is gradually increased with the rise of deformation of maize stubbles until the stress maximizes at the limit value.

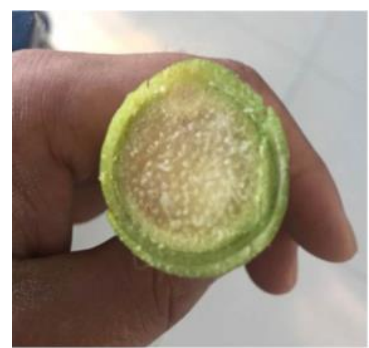

a. Sample of maize stubble



b. Schematic diagram of maize stubble
Figure 11 Cross section of maize stubble



a. Unilateral cutting mode

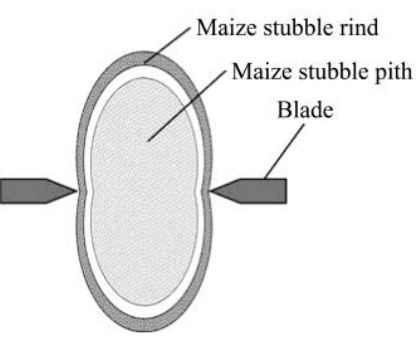

b. Symmetrical cutting mode
Figure 12 Schematic diagram of maize stubble deformation at the first cutting stage

At any random working speed of the first cutting stage, the $\mathrm{S} 1$ and S2 installed with bionic cutting blades compared with S3 and S4 both could rapidly reach the peak cutting torque, and the maximum cutting torque is smaller. The main reasons were that the edges of traditional blades continuously contacted with the stubble outer rind, but the segmented non-smooth edges of bionic cutting blades contacted it in a discontinuous way, with specific force analysis shown in Figure 13. Thus, it is clear from Equation (11) that the stubble rind, under the action of the bionic cutting blade, could quickly reach the limit stress and thereby rapidly reach the peak cutting torque ${ }^{[35]}$. Meanwhile, the outer rind was cut very quickly, which reduced the overall deformation of stubbles, so the maximum cutting torque of bionic cutting blades is smaller.
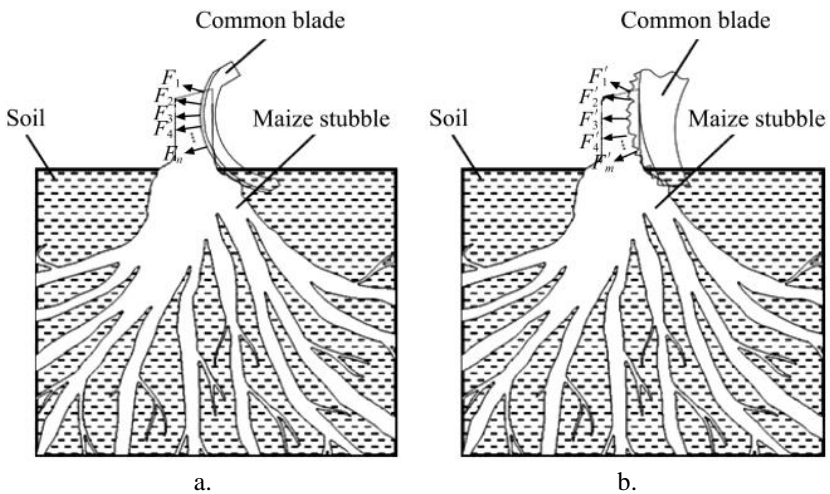

Note: $F_{1}-F_{n}$ mean the forces of the common blade to the stubble, $F_{1}{ }^{\prime}-F_{m}{ }^{\prime}$ mean the forces of the bionic blade to the stubble. The contact area between the common blade and stubble is much larger than that between the bionic blade and the stubble, which leads to the number of $n$ is greater than $m$.

Figure 13 Force analysis of maize stubble under the action of (a) common blade and (b) bionic blade

$$
\left\{\begin{array} { l } 
{ \frac { T } { \overline { r } _ { i } } = \sum _ { i = 1 } ^ { n } F _ { i } } \\
{ \frac { T } { \overline { r } _ { j } } = \sum _ { j = 1 } ^ { m } F _ { j } ^ { \prime } }
\end{array} \Rightarrow \left\{\begin{array}{l}
\operatorname{Max\tau }_{i}=\frac{\operatorname{Max}_{i}}{A} \\
\operatorname{Max\tau }_{j}^{\prime}=\frac{\operatorname{MaxF}_{j}^{\prime}}{A}
\end{array} \Rightarrow \operatorname{Max\tau }_{j}^{\prime}>\operatorname{Max}_{i}\right.\right.
$$

where, $T$ is the cutting torque, $\mathrm{N} \cdot \mathrm{m} ; \bar{r}_{i}$ is the equivalent cutting radius of common blades, $\mathrm{m} ; \bar{r}_{j}$ is the equivalent cutting radius of bionic blades, $\mathrm{m} ; \tau_{i}$ is the equivalent stress of common blades, $\mathrm{N} / \mathrm{m}^{2} ; \tau_{j}$ is the equivalent stress of bionic blades, $\mathrm{N} / \mathrm{m}^{2} ; A$ is the contact area between maize stubble and blades, $\mathrm{m}^{2}$.

At any random working speed, S1 which was installed with both bionic cutting blades and symmetrical cutting structure compared with S2 could more rapidly reach the peak cutting torque, and the maximum cutting torque was smaller. The main reasons for the above phenomena were that the resistance of blades originated from both stubbles and soils, and the stubbles cut by the blades were pulled modestly, with specific force analysis shown in Figure 14. If the pull was more evident, the soil-caused resistance was larger. According to Equation (12), the maximum cutting torque of symmetrical cutting mode was smaller than that of unilateral cutting mode. This is because symmetrical cutting can effectively reduce the initial acceleration of maize stubble, resulting in the decrease of the displacement of stubble.

$$
\left\{\begin{array} { l } 
{ \sum _ { j = 1 } ^ { n } F _ { j } - \sum _ { k = 1 } ^ { m } f _ { k } = M a _ { 1 } } \\
{ \sum _ { j = 1 } ^ { n } F _ { j } - \sum _ { k = 1 } ^ { m } f _ { k } - \sum _ { j = 1 } ^ { m } F _ { j } ^ { \prime } = M a _ { 2 } }
\end{array} \Rightarrow \left\{\begin{array}{l}
a_{1}>a_{2} \\
S_{1}=a_{1} t^{2} / 2 \Rightarrow S_{1}>S_{2} \\
S_{2}=a_{2} t^{2} / 2
\end{array}\right.\right.
$$


where, $M$ is the mass of maize stubble, $\mathrm{kg} ; S_{1}$ is the displacement of maize stubble at unilateral cutting mode, $\mathrm{m} ; S_{2}$ is the displacement of maize stubble at symmetrical cutting mode, $\mathrm{m}$.

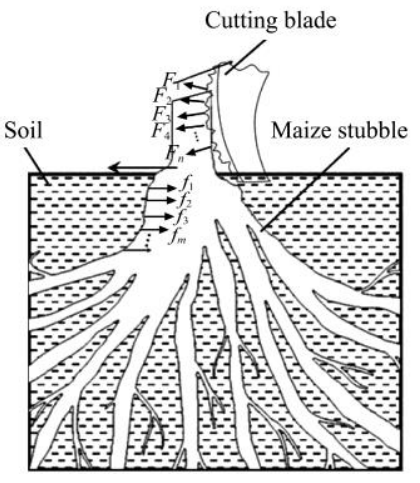

a.

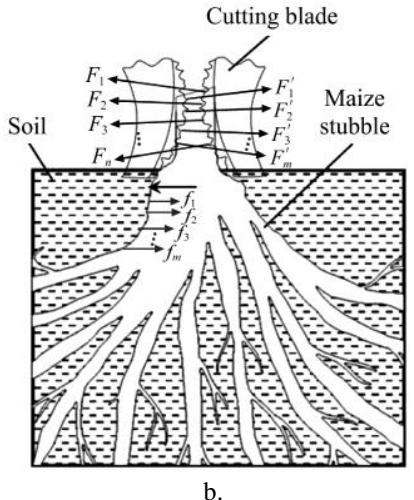

b.
Note: $F$ means the force of cutting blade to the stubble, $a$ means the acceleration of the stubble, $f$ means the force of soil to the stubble.

Figure 14 Force analysis of maize stubble at (a) unilateral cutting mode and (b) symmetrical cutting mode

\subsection{Analysis of the second cutting stage}

As the stubble outer rind was cut off, the cutting operation entered the second stage, where the outer rind and pith were both under continuous cutting and persistent extrusion (Figure 15). As the outer rind was gradually cut off, the cut-off part of the outer rind no longer acted on the blade, and thus, the cutting torque was gradually weakened. The S1 and S3 adopting the symmetrical cutting mode could cut the bilateral outer rind simultaneously, and thus, at this stage, the downtrend of cutting torque was more evident than those of S2 and S4 (Figure 15b). Since the bionic cutting blades could more quickly cut off the outer rind of maize stubbles, the downtrend of cutting torque from S1 at this stage was faster than that of S3.

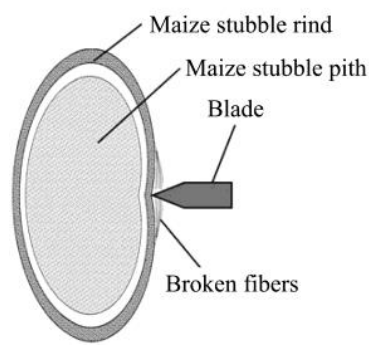

a. The unilateral cutting mode

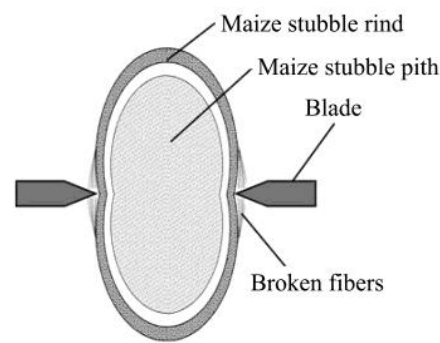

b. The symmetrical cutting mode

Figure 15 Schematic diagram of maize stubble deformation at the second cutting stage

\subsection{Analysis of the third cutting stage}

After the bilateral stubble outer rind was fully cut off in S1 and $\mathrm{S} 3$, the blades started to cut the pith and a small part of outer rind, but since the pith hardness was low, the cutting torques of S1 and $\mathrm{S} 3$ at this stage declined very quickly (Figure 16b). When S2 or S4 completely cut off one layer of outer rind, it started to cut the stubble pith and a small part of outer rind (Figure 16a). At this moment, the cutting torques of S2 and S4 declined quickly, but when a large part of the pith was cut off, S2 or S4 started to cut the outer skin at the other side, and thus, the cutting load rose again, producing the second peak.

\subsection{Analysis of the cutting power consumption}

Figure 17 shows the variation in cutting power consumption at different advancing speeds and cutting modes. The cutting power consumption of S1 was significantly the smallest, and declined $26.1 \%(4 \mathrm{~km} / \mathrm{h}), 21.9 \%(6 \mathrm{~km} / \mathrm{h}), 25.0 \%(8 \mathrm{~km} / \mathrm{h})$ compared with
S4; it was not significantly different between S2 and S3, but was significantly lower than that of S4 and dropped by $13.3 \%(4 \mathrm{~km} / \mathrm{h})$, $12.1 \%(6 \mathrm{~km} / \mathrm{h}), 15.4 \%(8 \mathrm{~km} / \mathrm{h})$ and $17.5 \%(4 \mathrm{~km} / \mathrm{h}), 14.6 \%$ $(6 \mathrm{~km} / \mathrm{h}), 12.9 \%(8 \mathrm{~km} / \mathrm{h})$. It is clear from Equation (11) that the bionic structure of locust mouthparts, as it could generate very small cutting torque, reduced the overall cutting power consumption. It is clear from Equation (12) The bionic movement patterns of locust mouthparts, as it could limit the displacement of stubbles, reduced both the cutting torque and cutting time, and thereby decreased the overall cutting power consumption. The coupling bionic stubble cutting device which possessed the characteristics of both showed the best operation effect.


a. The unilateral cutting mode

b. The symmetrical cutting mode

Figure 16 Schematic diagram of maize stubble deformation at the third cutting stage

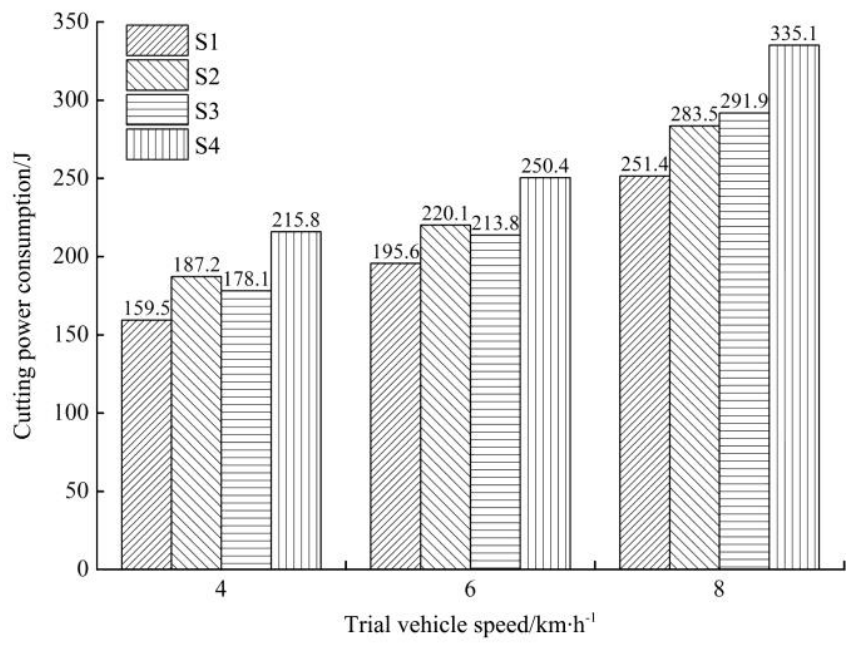

Figure 17 Variations in cutting power consumption at different advancing speeds and cutting modes

\section{Conclusions}

As the stubble cutting device was cutting maize stubbles, the cutting torque maximized when the compressed deformation of stubbles was the largest. The bionic multi-segment and serrate structure could increase the surface stress of stubbles, more rapidly reaching the limit stress, and reduced the compression deformation of stubbles. In terms of structure, the cutting torque and overall power consumption of the bionic cutting device were decreased by $18.7 \%-24.3 \%$ and $8.5 \%-15.4 \%$, respectively, compared with the common cutting device.

The bionic isokinetic and symmetrical mode, by reducing the horizontal displacement of stubbles during the cutting process, decreased the soil-induced resistance imposed on the blade, and shortened the operation time. In terms of the movement pattern, the cutting torque and overall power consumption of the bionic cutting device were decreased by $8.7 \%-14.8 \%$ and $11.1 \%-17.5 \%$, respectively, compared with the common cutting device. 
Based on the idea of coupling bionics, we designed a stubble cutting device which simulated both structure and cutting mode of locust mouthparts, and thereby succeeded in improving the cutting efficiency. Considering both structure and movement pattern, the cutting torque and overall power consumption of the bionic cutting device were decreased by $26.6 \%-31.6 \%$ and $21.9 \%-26.1 \%$, respectively, compared with the common cutting device. In summary, this work confirmed that the coupling bionics were superior to single bionics, which could be closer to the functional principle of organisms, thereby produced better bionic effects.

\section{Acknowledgements}

This work was supported by the project of National Key R\&D Program of China (No. 2018YFA0703300) and the National Natural Science Foundation of China (Grant no. 51705194) and Science and Technology Project of Jilin (20190301023NY) and National Natural Science Foundation of Jilin (20180101090JC).

\section{[References]}

[1] Lin Y M, Feng Z M, Wu W X, Yang Y Z, Zhou Y, Xu C C. Potential impacts of climate change and adaptation on maize in northeast China. Agronomy Journal, 2017; 109(4): 1476-1490.

[2] Komainda M, Taube F, Kluß C, Herrmann A. Above-and belowground nitrogen uptake of winter catch crops sown after silage maize as affected by sowing date. European Journal of Agronomy, 2016; 79: 31-42.

[3] Lim J G, Heo Y T, Lee S E, Jang W I, Min S G, Uhm S J, et al. A new modified cut standard straw vitrification technique reduces the apoptosis of mouse blastocysts and generates more live mouse offspring. CryoLetters, 2013; 34(6): 598-607.

[4] Dong W X, Hu C S, Chen S Y, Zhang Y M. Tillage and residue management effects on soil carbon and $\mathrm{CO}_{2}$ emission in a wheat-corn double-cropping system. Nutrient Cycling in Agroecosystems, 2009; 83(1): 27-37.

[5] Wegner B R, Osborne S L, Lehman R M, Kumar S. Seven-year impact of cover crops on soil health when corn residue is removed. BioEnergy Research, 2018; 11(2): 239-248.

[6] Hu G Q, Liu X, He H B, Zhang W, Xie H T, Wu Y Y, et al. Multi-seasonal nitrogen recoveries from crop residue in soil and crop in a temperate agro-ecosystem. Plos One, 2015; 10(7): e0133437.

[7] Liu T H, Liang Z H, Guo J D. Experimental comparison of litchi fruit stalk cutting force. Applied Engineering in Agriculture, 2012; 28(2): 297-302.

[8] Thompson B C, Murray E, Wallace G G. Graphite oxide to graphene. Biomaterials to bionics. Advanced Materials, 2015; 27: 7563-7582.

[9] Tian K P, Li X W, Zhang B, Chen Q M, Shen C, Huang J C. Design and test research on cutting blade of corn harvester based on bionic principle. Applied Bionics and Biomechanics, 2017; 6953786

[10] Ren L Q, Liang Y H. Biological couplings: Classification and characteristic rules. Science in China Series E: Technological Sciences, 2009; 52(10): 2791-2800.

[11] Qian Z H, Hong Y, Xu C Y, Ren L Q. A biological coupling extension model and coupling element identification. Journal of Bionic Engineering, 2009; 6(2): 186-195.

[12] Bhushan B. Biomimetics: lessons from nature - an overview. Philosophical Transactions of the Royal Society A-Mathematical Physical and Engineering Sciences, 2009; 367(1893): 1445-1486.

[13] Li J Q, Kou B X, Liu G M, Fan W F, Liu L L. Resistance reduction by bionic coupling of the earthworm lubrication function. Science China Technological Sciences, 2010; 53(11): 2989-2995.

[14] Lomer C J, Bateman R P, Johnson D L, Langewald J, Thomas M. Biological control of locusts and grasshoppers. Annual Review of Entomology, 2001; 46: 667-702.
[15] Jia H L, Li C Y, Zhang Z H, Wang G. Design of Bionic Saw Blade for Corn Stalk Cutting. Journal of Bionic Engineering, 2013; 10(4): 497-505.

[16] Simpson S J, Raubenheimer D. The hungry locust. Advances in the Study of Behavior, 2000; 29: 1-44.

[17] Zhou M, Sun L, Du X, Zhao Y, Xin L. Optimal Design and Experiment of Rice Pot Seedling Transplanting Mechanism with Planetary Bezier Gears. Transactions of the ASABE, 2014; 57(6): 1537-1548.

[18] Uyanik I, Catalbas B. A low-cost feedback control systems laboratory setup via Arduino-Simulink interface. Computer Applications in Engineering Education, 2018; 26(3): 718-726.

[19] Guo G, Yue W. Autonomous platoon control allowing range-limited sensors. IEEE Transactions on Vehicular Technology, 2012; 61(7): 2901-2912.

[20] Yin Z, Fu Y C, Xu J H, Li H, Cao Z Y, Chen Y R. A novel single driven ultrasonic elliptical vibration cutting device. The International Journal of Advanced Manufacturing Technology, 2017; 90(9-12): 3289-3300.

[21] Wu Y R, Tran V T. Transmission and load analysis for a crowned helical gear pair with twist-free tooth flanks generated by an external gear honing machine. Mechanism and Machine Theory, 2016; 98: 36-47.

[22] Israel W, Tiemann I, Metz G, Yamaryo Y, Maeda F, Shimomura T. An international length comparison at an industrial level using a photoelectric incremental encoder as transfer standard. Precision Engineering, 2003; 27(2): 151-156.

[23] Flammini A, Marioli D, Taroni A. A low-cost diagnostic tool for stepping motors. IEEE Transactions on Instrumentation and Measurement, 2001; 50(1): 157-162.

[24] Wang H F, Xu L M, Zhang J J. Design and Simulation of Pineapple Picking-Gripper Based on MATLAB Image Processing. Sensor Letters, 2013; 11(6-7): 1210-1216.

[25] Dubey S, Gusain D, Sharma Y C. Kinetic and isotherm parameter determination for the removal of chromium from aqueous solutions by nanoalumina, a nanoadsorbent. Journal of Molecular Liquids, 2016; 219: $1-8$.

[26] Xu Y J, Lin J D. Effect of temperature, salinity, and light intensity on the growth of the green macroalga, Chaetomorpha linum. Journal of the World Aquaculture Society, 2008; 39(6): 847-851.

[27] Zhao J L, Huang D Y, Jia H L, Zhuang J, Guo M Z. Analysis and experiment on cutting performances of high-stubble maize stalks. International Journal of Agricultural and Biological Engineering, 2017; 10(1): 40-52.

[28] Zhou W Q, Wang J W, Tang H. Structure optimization of cam executive component and analysis of precisely applying deep-fertilization liquid fertilizer. Int J Agric \& Biol Eng, 2019; 12(4): 104-109.

[29] Rife J C, Miller M M, Sheehan P E, Tamanaha C R, Tondra M, Whitman L J. Design and performance of GMR sensors for the detection of magnetic microbeads in biosensors. Sensors and Actuators A: Physical, 2003; 107(3): 209-218.

[30] Cao P L, Yang C, Chen Y W, Chen B Y, Talalay P. Experimental study of the drilling process in debris-rich ice. Cold Regions Science and Technology, 2015; 120: 138-144.

[31] Maughan J D, Mathanker S K, Fehrenbacher B M, Hansen A C. Impact of cutting speed and blade configuration on energy requirement for Miscanthus harvesting. Applied Engineering in Agriculture, 2014; 30(2): $137-142$.

[32] Tong J, Ji W F, Jia H L, Chen D H, Yang X W. Design and tests of biomimetic blades for soil-rototilling and stubble-breaking. Journal of Bionic Engineering, 2015; 12(3): 495-503.

[33] Ma Y H, Wu S Y, Zhuang J, Tong J, Xiao Y, Qi H Y. The Evaluation of Physio-Mechanical and Tribological Characterization of Friction Composites Reinforced by Waste Corn Stalk. Materials, 2018; 11(6): 901.

[34] Jiang H X, Du C L, Liu S Y, Gao K D. Fractal characteristic of rock cutting load time series. Discrete Dynamics in Nature and Society, 2014; 915136.

[35] Kang M S, Din A K, Zhang Y, Magari R. Combining ability for rind puncture resistance in maize. Crop Science, 1999; 39(2): 368-371. 